Journal of Engineering and Applied Sciences 14 (1): 265-269, 2019

ISSN: 1816-949X

(C) Medwell Journals, 2019

\title{
Concentration of Molybdenum Oxides and Salts in a Supercritical Water Medium
}

\author{
${ }^{1}$ A.U. Aetov, ${ }^{1}$ S. V. Mazanov, ${ }^{1}$ A.R. Gabitova, ${ }^{1}$ Z.I. Zaripov, ${ }^{1}$ R.A. Usmanov, \\ ${ }^{2}$ R.A. Kayumov and ${ }^{1}$ F.M. Gumerov \\ ${ }^{1}$ Kazan State Research Technological University, Kazan, Russia \\ ${ }^{2} \mathrm{NPF}$ EITEK LLC, Nizhnekamsk, Russia
}

\begin{abstract}
The results of an experimental study of the oxidation of industrial 5\% water runoff of the propylene epoxidation process carried out under supercritical fluid conditions $(\mathrm{T}=673-873 \mathrm{~K}, \mathrm{P}=25 \mathrm{MPa}$ ) on a continuous plant using oxygen as the oxidant are presented. The Chemical Oxygen Demand (COD), pH and mass spectra of the initial sample and reaction products were determined. The regularities of the efficiency of water runoff oxidation on the temperature and duration of the reaction are established. The elemental composition of the solid sediment is determined.
\end{abstract}

Key words: Molybdenum-containing water runoff, supercritical fluid conditions, oxidation, chemical oxygen demand, solid sediment, COD

\section{INTRODUCTION}

Nowadays, the share of chemical and petrochemical industries is growing rapidly as a result of which the question of the environmental component of these industries arises (Gumerov et al., 2012; Gayazova et al., 2013). The main problem of any chemical production is waste disposal (Kim and Kim, 2011; Chin et al., 1997; Vostrikov et al., 2017). If inert and low-hazard industrial wastes are mostly disposed of by landfill, then for toxic waste it is first necessary to carry out thermal neutralization or physico-chemical neutralization (Yang et al., 2017; Xu et al., 2015; Cao et al., 2011). One of the wastes, subjected to thermal neutralization is the waste of the process of hydroperoxide epoxidation of propylene for the joint production of styrene and propylene oxide which is industrially implemented at PJSC Nizhnekamsk Neftekhim. A distinctive feature of this process is the use of molybdenum compounds soluble in the reaction mass which are used as a catalyst. During the reaction, the catalytic complex is destroyed and removed together with the reaction products in the form of a heavy fraction. After washing, the spent alkaline waste that is formed makes it difficult to separate the waste by distillation or rectification due to the presence of sodium salts and residual alkali which are emulsifiers. As a result, after thermal neutralization, the molybdenum complex is irretrievably lost with waste.

In the literature there is information on the extraction of molybdenum from alkaline waste. The research by Kirpichnikov et al. (1986) describes the return of still bottoms in the process for recycling molybdenum but due to the high corrosivity of the residues, it is not industrially implemented. The researchers carried out the isolation of molybdenum with organic peroxides by treating them with aqueous solutions of alkaline agents (Kaplan, 1970). But in this method there are large losses of target products, soluble in water and pollution of the aqueous phase which complicates the regeneration of the catalyst. A known method of molybdenum extraction with aqueous solutions of acetic, formic, propionic and butyric acids (Askins, 1893). However, as much as possible with this method, no more than $93 \%$ of the molybdic product can be extracted. In addition, the high volumetric ratio of the still bottom residue to the extractant, the need for temperature control, the duration of the process complicate the technology of catalyst extraction.

To solve the problem of the molybdenum extraction, the present research considers the possibility of using Supercritical Fluid (SCF) technologies. There are at least three process options. The first option is based on the use of the SCF extraction process. The second method involves the reaction of supercritical oxidation of waste in the aqueous medium. And the third option is based on the combined use of SCF extraction and Supercritical Water Oxidation (SCWO). As for SCF extraction, the researchers of this study have previously been able to obtain results on the extraction of molybdenum and the oxidizability of organic waste contained in the water run-off of the olefin epoxidation process (Kayumov et al., 2012).

Corresponding Author: A.U. Aetov, Kazan State Research Technological University, Kazan, Russia 
The present research is devoted to the study of the second solution to the problem. The use of water in the SCF state $\left(t>374^{\circ} \mathrm{C}, \mathrm{p}>22.1 \mathrm{MPa}\right)$ allows you to dissolve any organic compounds containing difficult-to-wash substances as well as complex mixtures of organic substances. There are researches on the disposal of water run-off by the SCWO method (Psarov, 2006; Veriansyan and Jae-Duck, 2007).

It should also be noted that in most cases Hydrogen peroxide $\left(\mathrm{H}_{2} \mathrm{O}_{2}\right)$ is used as an oxidant which is not profitable from the point of view of the process economic costs. The use of oxygen contained in the air is a promising solution and of course is also an urgent task of this study (Shin et al., 2009; Gong et al., 2008; Leusbrock et al., 2008; Lee et al., 2006).

\section{MATERIALS AND METHODS}

The studied runoff was the industrial water runoff of styrene and propylene oxide production process at PJSC Nizhnekamskneftekhim of the following composition:

- Ethylbenzene $\mathrm{C}_{6} \mathrm{H}_{5} \mathrm{CH}_{2} \mathrm{CH}_{3}-2.5 \%$ wt.
- Acetophenone $\mathrm{CH}_{3} \mathrm{COC}_{6} \mathrm{H}_{5}-1 \%$ wt.

- Methylphenylcarbinol $\mathrm{C}_{6} \mathrm{H}_{5} \mathrm{CH}(\mathrm{OH}) \mathrm{CH}_{3}-6.5 \%$ wt.

- Phenol $\mathrm{C}_{6} \mathrm{H}_{5} \mathrm{OH}-2.5 \%$ wt.

- Propylene glycol $\mathrm{C}_{3} \mathrm{H}_{8} \mathrm{O}_{2}-12 \%$ wt.

- Molybdenum Mo (pure metal)-0.2\% wt.

- Water $\mathrm{H}_{2} \mathrm{O}-40 \%$ wt.

As part of the research to develop the process of waste utilization in the SCF conditions of the reaction mixture, an original experimental continuous plant was used (Fig. 1) (Gumerov et al., 2017).

A distinctive feature of this plant is the use of a high-frequency induction heater (13). The advantage of induction heating is that the heat is completely transferred to the reaction mixture while achieving a high heating rate, increasing its uniformity. High concentration and precise localization of the energy of the electromagnetic field provides a short cycle and high performance of the chemical process.

The degree of contamination of wastewater and the oxidation reaction product was determined by the values of $\mathrm{COD}$, obtained on the photometric analyzer "Expert-003-COD" with a thermal reactor for 26 samples in

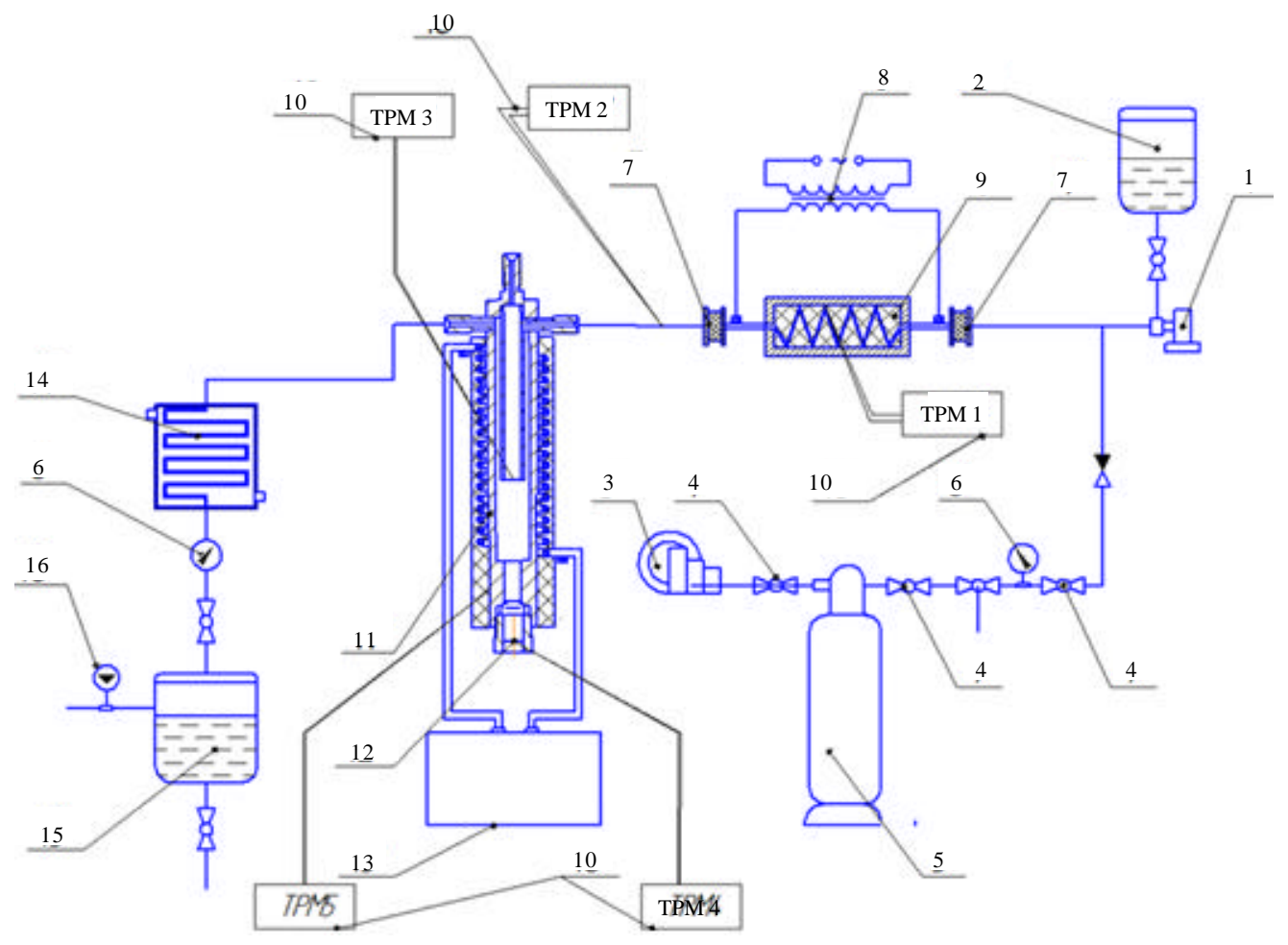

Fig. 1: Schematic diagram of the SCWO continuous plant: 1) High-pressure pump; 2) Capacity for the initial run-off, air; 3) Air compressor; 4) Valve; 5) Receiver; 6) Manometer; 7) Current isolating element; 8) Step-down transformer; 9) Heat exchanger for heating the feed mixture; 10) Temperature sensor (thermocouple); 11) Reactor; 12) Sediment collection chamber; 13) High frequency induction heater HF-30; 14) Fridge; 15) Wastewater collection tank and 16) Gas flowmeter 
accordance with GOST R 52708-2007 (Aetov et al., 2016). The essence of the COD measurement method was to treat water samples with sulfuric acid and potassium bichromate at a given temperature in the presence of silver sulfate (oxidation catalyst) and mercuric (II) sulfate, used to reduce the effect of chlorides. The COD value in a given concentration range was determined by measuring the optical density of the test solution at a given wavelength of 430 or $605 \mathrm{~nm}$ (depending on the measurement range) using the calibration dependence of the optical density of the solution on the COD value. The oxidation efficiency $\mathrm{X}$ was determined by Eq. 1:

$$
\mathrm{X}=1-\frac{\mathrm{COD}_{\mathrm{ox}}}{\mathrm{COD}_{\text {in }}}
$$

Where:

$\mathrm{COD}_{\text {in }}=$ Chemical Oxygen Demand for the initial flow $\left(\mathrm{mgO}_{2} / \mathrm{L}\right)$

$\mathrm{COD}_{\mathrm{ox}}=$ Chemical Oxygen Demand for oxidized water runoff $\left(\mathrm{mgO}_{2} / \mathrm{L}\right)$

The excess oxygen used in the reaction was calculated using the following Eq. 2 :

$$
\mathrm{O}_{2}(\%)=\frac{\left[\mathrm{O}_{2}\right]_{\mathrm{a}}}{\left[\mathrm{O}_{2}\right]_{\mathrm{s}}} \times 100
$$

Where:

$\left[\mathrm{O}_{2}\right]_{\mathrm{a}}=$ The actual concentration of oxygen supplied to the reactor $(\mathrm{mmol} / \mathrm{L})$

$\left[\mathrm{O}_{2}\right]_{\mathrm{s}}=$ The stoichiometric oxygen concentration based on the $\mathrm{COD}$ of waste water $(\mathrm{mmol} / \mathrm{L})$

The residence time in the flow mode $(\tau)$ was determined by Eq. 3 :

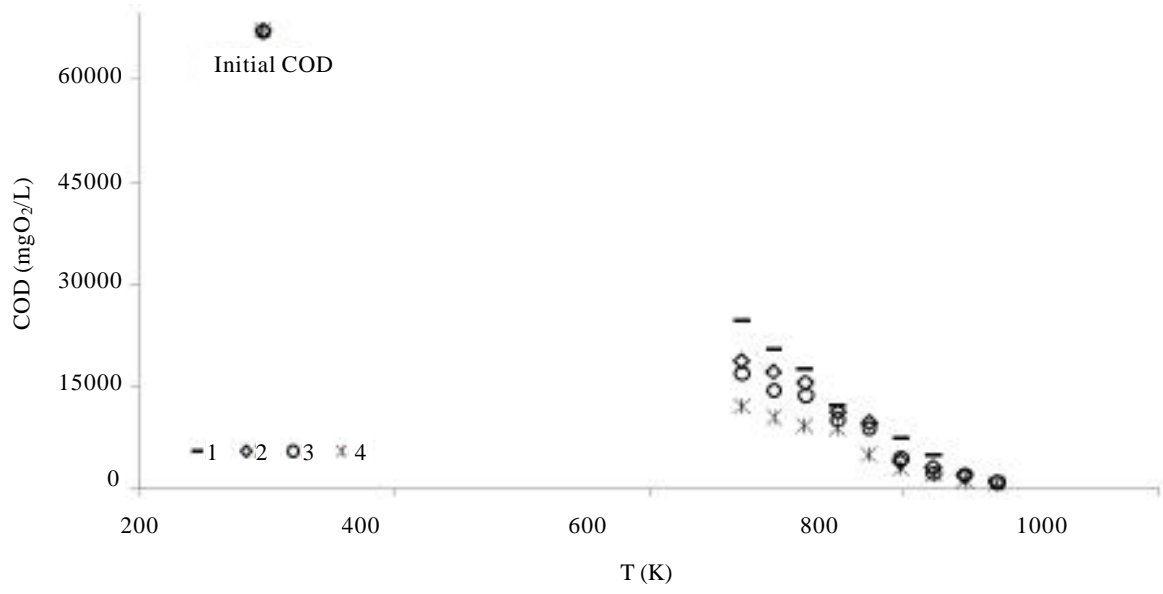

Fig. 2: Dependence of $\mathrm{COD}$ values $\left(\mathrm{mgO}_{2} / \mathrm{L}\right)$ on the influence of the temperature of the SCWO process at $\mathrm{P}=25 \mathrm{MPa}$ with an excess of oxygen: $1-100 \%, 2-200 \%, 3-300 \%, 4-400 \%$

$$
\tau=\frac{\mathrm{V}}{\mathrm{Q}_{1}+\mathrm{Q}_{2}} * \frac{\mathrm{V}_{0}}{\mathrm{~V}_{\mathrm{r}}} * 60
$$

Where:

$\mathrm{V} \quad=$ Reactor Volume $(\mathrm{mL})$

$\mathrm{V}_{0}$ and $\mathrm{V}_{\mathrm{r}}=$ The specific volumes of the initial runoff at room temperature, atmospheric pressure and under the reaction conditions $\left(\mathrm{m}^{3} / \mathrm{kg}\right)$, respectively

$\mathrm{Q}_{1} \quad=$ Feed rate of the initial water run-off $(\mathrm{mL} / \mathrm{min})$

$\mathrm{Q}_{2} \quad=$ Air flow rate $(\mathrm{mL} / \mathrm{min})$

The inorganic residue with the target component, molybdenum was analyzed on a portable S1 TITAN XRF spectrometer.

\section{RESULTS AND DISCUSSION}

The oxidation of $5 \%$ molybdenum-containing water runoff was carried out with an excess of atmospheric oxygen of $100-400 \%$ in the temperature range $\mathrm{T}=673-873$ $\mathrm{K}$ at a pressure $\mathrm{P}=25 \mathrm{MPa}$ in the dynamic mode. Figure 2 and 3 present the COD values depending on the process temperature and oxygen excess.

An increase in temperature and an excess of oxidant contribute to a greater oxidation of the waste. The minimum $\mathrm{COD}$ value equal to $713 \mathrm{mgO}_{2} / \mathrm{L}$ is achieved at the maximum temperature $(\mathrm{T}=873 \mathrm{~K})$ and $400 \%$ excess oxygen. In this case, the estimated residence time of the mixture in the reactor is $230 \mathrm{sec}$. Obtaining such a result is comparable and even exceeds the COD values for process water $\left(\sim 1000 \mathrm{mgO}_{2} / \mathrm{L}\right)$ which indicates almost complete oxidability and recycling of industrial waste.

Table 1 shows the data on the efficiency of oxidation of the initial water runoff according to the results of the influence of the process temperature and excess oxygen. 
Table 1: Efficiency of oxidation $(X)$ of the industrial water runoff reaction products

\begin{tabular}{|c|c|c|c|c|}
\hline${\underline{T_{\text {reactar }}}}(\mathrm{K})$ & Excess $\left(\mathrm{O}_{2}, \%\right)$ & Efficiency of oxidation $(\mathrm{X})$ & Excess $\left(\mathrm{O}_{2}, \%\right)$ & Efficiency of oxidation $(\mathrm{X})$ \\
\hline 673 & 100 & 0.63 & 300 & 0.75 \\
\hline 698 & & 0.70 & & 0.78 \\
\hline 723 & & 074 & & 0.80 \\
\hline 748 & & 0.82 & & 0.85 \\
\hline 773 & & 0.86 & & 0.87 \\
\hline 798 & & 0.89 & & 0.94 \\
\hline 823 & & 0.93 & & 0.97 \\
\hline 848 & & 0.97 & & 0.97 \\
\hline 873 & & 0.98 & & 0.98 \\
\hline 673 & 200 & 0.72 & 400 & 0.82 \\
\hline 698 & & 0.74 & & 0.84 \\
\hline 723 & & 0.77 & & 0.86 \\
\hline 748 & & 0.83 & & 0.87 \\
\hline 773 & & 0.86 & & 0.93 \\
\hline 798 & & 0.94 & & 0.95 \\
\hline 823 & & 0.95 & & 0.96 \\
\hline 848 & & 0.97 & & 0.98 \\
\hline$\underline{873}$ & & 0.98 & & 0.99 \\
\hline
\end{tabular}

Table 2: Mass fractions of the dry sediment components (given in pure form)

\begin{tabular}{|c|c|c|c|c|c|c|c|c|c|c|}
\hline ient & $\mathrm{Zn}$ & $\mathrm{Fe}_{2} \mathrm{O}_{3}$ & $\mathrm{Cr}$ & Mo. & $\mathrm{Ag}$ & $\mathrm{Cu}$ & $\mathrm{SiO}_{2}$ & $\mathrm{Ni}$ & $\mathrm{Al}_{2} \mathrm{O}_{3}$ & $\mathrm{CaO}$ \\
\hline Content (\%) & 38.8 & 8.2 & 2.9 & 2.3 & 1.4 & 0.9 & 0.8 & 0.8 & 0.6 & 0.5 \\
\hline
\end{tabular}

Bold heading and value are signific ant

Table 3: The content of molybdenum in the liquid fraction

Sample Sample of the water run-off (Bottom fraction) Sample of the water run-off (upper fraction) $\quad$ Purified water run-off (with minimum COD)

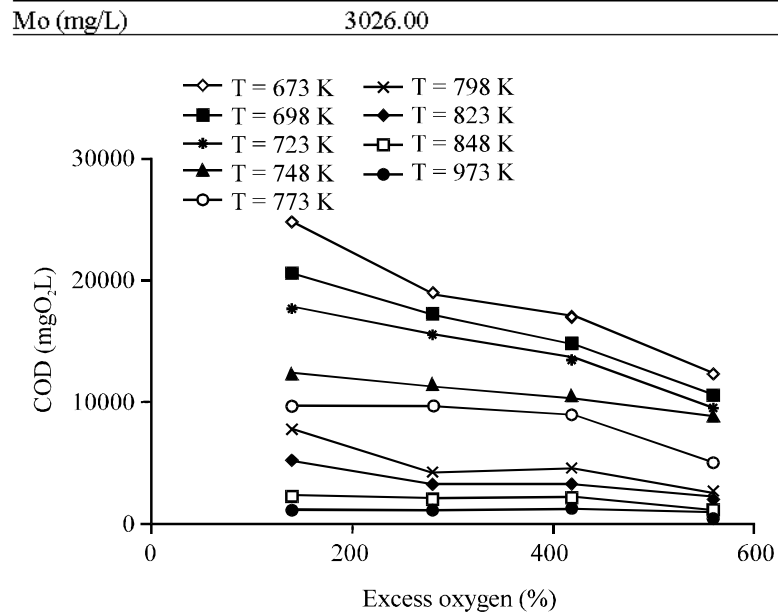

Fig. 3: Dependence of $\mathrm{COD}$ values $\left(\mathrm{mgO}_{2} / \mathrm{L}\right)$ on excess oxygen $(\mathrm{P}=25 \mathrm{MPa}, \mathrm{T}=673-873 \mathrm{~K})$

The efficiency of oxidation is inversely proportional to the value of COD. With a decrease in COD, the efficiency of oxidation increases. As a result, 99\% conversion is achieved at the maximum studied parameters of the process.

Table 2 shows the results of mass spectrometric analysis of dry sediment. A small amount of molybdenum $(2.3 \%)$ is explained by a significant dilution of the industrial runoff itself ( $5 \%$ solution).

In addition to the obtained solid precipitate of the target component, some of the unremoved molybdenum complex remained in the liquid fraction which is clearly shown in Table 3.

\section{CONCLUSION}

A study of the process of supercritical water oxidation $(\mathrm{T}=673-873 \mathrm{~K}, \mathrm{P}=25 \mathrm{MPa})$ of molybdenum-containing water run-off was carried out using air oxygen as an oxidant in a continuous plant. A significant decrease in the COD value of the reaction product in comparison with the COD of the initial water runoff has been established. The optimal conditions for the implementation of the reaction in the considered range of process parameters can take the temperature $\mathrm{T}=873 \mathrm{~K}$, the reaction time is $230 \mathrm{sec}$ at a pressure of $25 \mathrm{MPa}$ at which the minimum $\mathrm{COD}$ value $=713 \mathrm{mgO}_{2} / \mathrm{L}$ is reached. In the obtained samples of the inorganic residue, the presence of molybdenum was established in the amount of $2.3 \mathrm{wt} . \%$ which is the target product for subsequent extraction.

\section{ACKNOWLEDGEMENT}

The reported study was funded by RFBR according to the research project No. 18-29-06041.

\section{REFERENCES}

Aetov A.U., R.A. Usmanov, R.R. Gabitov, S.V. Mazanov and M.S. Kurbangeleev, 2016. Experimental setup for the study of supercritical water oxidation in continuous mode and the principles of its operation. Bull. Kazan Technol. Univ., 19: 37-39. 
Askins, J., 1893. A pparatus for the wanu facture of gas. Patent No. 491,398, United States Patent Office, Washington, DC., USA.

Cao, C., L. Guo, Y. Chen, S. Guo and Y. Lu, 2011. Hydrogen production from supercritical water gasification of alkaline wheat straw pulping black liquor in continuous flow system. Intl. J. Hydrogen Energy, 36: 13528-13535.

Chin, K., K. Fouhy and T. Kamiya, 1997. Advanced oxidation mission-search and destroy. Chem. Eng., 104: 39-39.

Gayazova, E.S., R.A. Usmanov, F.M. Gumerov, S.V. Friedland and Z.I. Zaripov et al., 2013. The combination of coagulation-flocculation method and the SCWO in the waste water treatment problems. Intl. J. Anal. Mass Spectrom. Chromatogr., 1: $48-54$.

Gong, W.J., F. Li and D.L. Xi, 2008. Oxidation of industrial dyeing wastewater by supercritical water oxidation in transpiring-wall reactor. Water Environ. Res., 80: 186-192.

Gumerov, F.M., R.A. Kayumov, R.A. Usmanov, A.A. Sagdeev and I.S. Abdullin et al., 2012. Waste management in propylene epoxidation process with the use of supercritical fluid media. Am. J. Anal. Chem., 3: 950-957.

Gumerov, F.M., R.A. Usmanov, S.V. Mazanov, A.R. Gabitova and A.I. Kourdiyukov et al., 2017. Theoretical and experimental study of reaction of transesterification of vegetable oils in an alcohol environment in the SBCF and SCF conditions with the ultrasonic emulsification of reaction mixture and the use of heterogeneous catalysts. Intl. J. Anal. Mass Spectrom. Chromatogr., 5: 40-45.

Kaplan, R., 1970. Process for preparing oxirane compound. Patent No. 3523956. United States Patent and Trademark Office, Washington, DC, USA.

Kayumov, R.A., A.T. Galimov, A.A. Sagdeev, A.A. Petukhov and F.M. Gumerov, 2012. Extraction of the waste components of propylene epoxidation process with supercritical $\mathrm{CO}_{2}$. Supercrit. Fluids Theor. Pract., 1: 3-12.
Kim, D.E. and M.H. Kim, 2011. Two layer heat transfer model for supercritical fluid flow in a vertical tube. J. Supercrit. Fluids, 58: 15-25.

Kirpichnikov, P.A., V.V. Beresnev and L.M. Popova, 1986. [Al'bom Technological Schemes of the Main Production of the Synthetic Rubber Industry]. Khimiya Publisher, Leningrad, Russia, Pages: 224 (In Russian).

Lee, H.C., S.H. Son, K.Y. Hwang and C.H. Lee, 2006. Surface chemical analysis on the corrosion of alloys in the supercritical water oxidation of halogenated hydrocarbon. Ind. Eng. Chem. Res., 45: 3412-3419.

Leusbrock, I., S.J. Metz, G. Rexwinkel and G.F. Versteeg, 2008. Quantitative approaches for the description of solubilities of inorganic compounds in near-critical and supercritical water. J. Supercrit. Fluids, 48: 117-127.

Psarov, S.A., 2006. Thermal effects of organic matter oxidation in supercritical water. MSc Thesis, Stellenbosch University, Stellenbosch, South Africa.

Shin, Y.H., N.C. Shin, B. Veriansyah, J. Kim and Y.W. Lee, 2009. Supercritical water oxidation of wastewater from acrylonitrile manufacturing plant. J. Hazard. Mater., 163: 1142-1147.

Veriansyah, B. and K. Jae-Duck, 2007. RETRACTED: Supercritical water oxidation for the destruction of toxic organic wastewaters: A review. J. Environ. Sci., 19: $513-522$.

Vostrikov, A.A., O.N. Fedyaeva, A.V. Shishkin and M.Y. Sokol, 2017. Oxidation of hydrogen sulfide and corrosion of stainless steel in gas mixtures containing $\mathrm{H}_{2} \mathrm{~S}, \mathrm{O}_{2}, \mathrm{H}_{2} \mathrm{O}$ and $\mathrm{CO}_{2}$. J. Eng. Thermophys., 26: 314-324.

$\mathrm{Xu}$, D., S. Wang, J. Zhang, X. Tang and Y. Guo et al., 2015. Supercritical water oxidation of a pesticide wastewater. Chem. Eng. Res. Des., 94: 396-406.

Yang, B., Z. Shen, Z. Cheng and W. Ji, 2017. Total nitrogen removal, products and molecular characteristics of $14 \mathrm{~N}$-containing compounds in supercritical water oxidation. Chemosphere, 188: 642-649. 